\title{
THE USE OF OMEGA-3 PUFAS IN PAIN THERAPY
}

\author{
Carlos H Laino* \\ Biotechnology Institute, Center for Research and Innovation Technological, National University of La Rioja, Argentina
}

Submission: June 26, 2017; Published: July 14, 2017

*Corresponding author: Carlos H Laino, Biotechnology Institute, Center for Research and Innovation Technological, National University of La Rioja, Av Luis Vernet y Apostol Felipe, Argentina, South America, Tel: 011-54-380-466915, Fax: 011-54-380-466915;

Email: carloslaino25@gmail.com

\section{Abstract}

Acute and chronic pain afflicts millions of patients each year worldwide. However, inadequate management of acute pain negatively impacts numerous aspects of patient health and may increase the risk of developing chronic pain, which can have a profound impact on the body's endocrine, neurologic, musculo-skeletal, cardiovascular and immune systems. Although opioids are the preferred treatment for most moderate to severe acute and chronic pains, their side effects can interfere with and thus limit their clinical effectiveness. Morphine is one of the most used opioids for the acute and chronic control of moderate to severe pain. However, side effects are frequently observed in patients receiving morphine during chronic pain treatment, which can lead to the interruption of treatment.

Recently, an increasing number of preclinical and clinical studies have demonstrated the beneficial effects of omega-3 PUFAs in different clinical situations with inflammatory pain. This review examines a number preclinical and clinical studies using omega-3 PUFAs (eicosapentaenoic acid and docosahexaenoic acid) as a monotherapy or as an adjunct to morphine in the treatment of pain and suggests a role for omega-3 PUFAs as adjuncts to opioids in pain therapy, which might contribute to a reduction in the occurrence of typical side-effects common to morphine use.

Keywords: Docosahexaenoic acid; Eicosapentaenoic acid; Omega-3 polyunsaturated fatty acid; Pain; Nutraceuticals

Abbreviations: AA: Arachidonic Acid; ALA: Alpha-Linolenic Acid; ASICs: Acid-Sensing Ion Channels; DGLA: Dihomo- $\gamma$-linolenic Acid; DHA: Docosa Hexaenoic Acid; EFAs: Essential Fatty Acids; EPA: Eicosa Pentaenoic Acid; EDP: Epoxy Docosa Pentaenoic Acid; EEQ: Epoxy Eicosatetraenoic Acid; GLA: $\gamma$-linolenic Acid; GPR40: G-Protein-Coupled receptor 40; LA: Linoleic Acid; LOX: Lip Oxygenase; PLA2: Phospho Lipase A2; omega-3 PUFAs: omega-3 Poly Unsaturated Fatty Acids; omega-6 PUFAs: omega-6 Polyunsaturated Fatty Acids; RvE: Resolvin E; RvD: Resolvin D; TRPV1: Transient Receptor Potential Vanilloid type 1

\section{Introduction}

The Fatty acids (FA) are lipids that represent a significant percentage of the daily caloric intake in the diet of mammals. All FA are carboxylic acids (carboxylic group) with hydrocarbon chains of 4 to 36 carbon, with the physical and chemical characteristics of the FA (eg, their melting point or solubility in water) and also their nutritional properties (energy content, digestibility, metabolic effects, etc.) depending on the number of carbon atoms in each molecule, the number of double bonds that they possess (double bonds between carbons), the position occupied by their double bonds in the chain and their isomerisms (cis or trans).

FA can be classified according to the length of the chain, the number, position and configuration of the double bonds, as well as the additional existence of other functional groups.
With respect to the carbon chain length, the FAs are classified as: short chain (less than 10 carbons), medium chain (12 or 14 carbons) or long chain (16 carbons or more).Also, fatty acids are classified as saturated fatty acids that have no double bonds or unsaturated fatty acids that have double or triple bonds. Based on the number of double bonds present, unsaturated fatty acids are further divided into monounsaturated fatty acids with only one double bond and polyunsaturated fatty acids (PUFAs) with two or more double bonds. When the first double bond is located between the $9-10$ carbon atoms (counting from the terminal methyl group), these molecules originate the family or series of FA called omega-9.When the double bond is between the 6 -7 carbon atoms, this originates the omega- 6 family, and for the double-bond between the 3- 4 carbon atoms, the family omega3arises (Figure 1). 


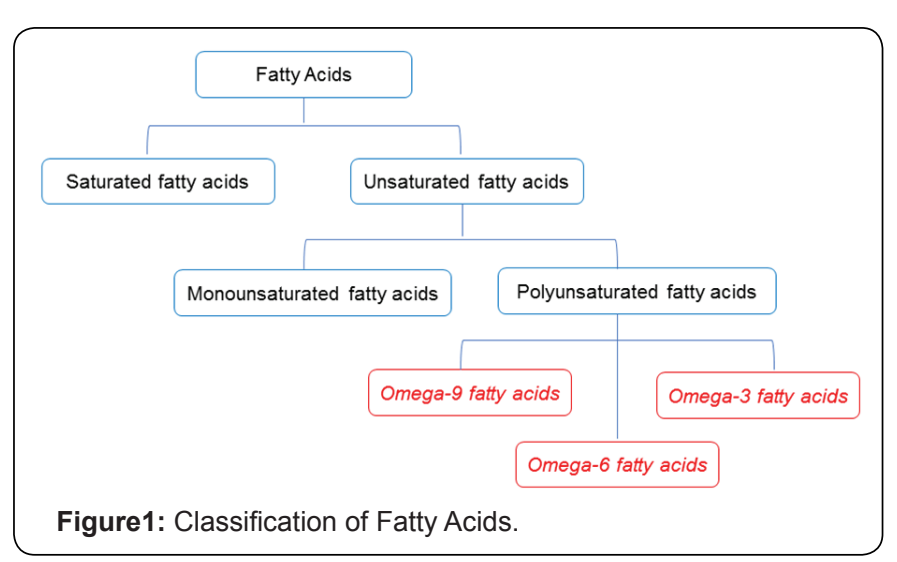

\section{Dietary sources of Omega-3 PUFAs}

Some marine species, such asmammals, fish and crustaceans, are characterized by accumulating in their tissues relatively large amounts of omega-3 PUFAs, especially eicosapentaenoic acid (EPA) and docosahexaenoic acid (DHA).These animals can incorporate these fatty acids mainly with the food, since they have an inefficient biosynthesis of EPA and DHA from ALA [1]. The marine food chain depends on primary producers such as marine phytoplankton and zooplankton, because they can cumulative omega-3 PUFAs [2,3].These primary marine producers can effectively incorporate PUFAs with long chains from ALA and LA via a series of desaturation and elongation reactions, such as EPA and DHA. An increase in the fat content of marine animals indicates a resulting higher content of EPA and DHA in their meat and the oil obtained from them.

EPA accumulates mainly in adipose tissue, while $90 \%$ or more of DHA constitutes the nervous tissue of these animals, mainly in the form of phosphatidylserine and phosphatidylethanolamine. In this way, fish such as tuna, herring, mackerel, sardine, jurel, salmon and anchovy are important sources of EPA and DHA [4]when consumed as meat or in the products of their industrialization (mainly flour and oil). Other sources of omega-3 PUFAs are vegetables, with vegetable oils being the main source of ALA, such as linseed and primrose. In particular, ALA is present in the chloroplast of green leaves of vegetables and contain only shorter-chain omega-3 PUFAs and low or absent levels of EPA and DHA $[5,6]$.

\section{Essential Fatty Acids}

Essential fatty acids (EFAs) correspond to both the $\mathrm{n}-6$ and n-3 series, as in linoleic acid (LA) and alpha-linolenic acid (ALA), respectively [7].They are called essential because they are indispensable for human life and man cannot synthesize them, so their incorporation with the diet is required in a daily proportion of 1 to $2 \%$ of the total lipids consumed [8]. A lack of EFAs, AL and ALA is manifested by specific signs, including lack of growth, skin lesions, less pigmentation of the skin, loss of muscle tone, degenerative changes in the kidney, lung and liver, an increase in basal metabolism [9], and is also a possible cause of hyperactivity in children [10] Moreover, it can produce alterations in cell permeability, water balance disorders, increased susceptibility to infections and changes in electroencephalogram and electrocardiogram [11,12]. The common signs of EPA and DHA deficiency are much less obvious than for ALA. These include heart problems and/or poor circulation, visual disturbances, changes in the skin (dry skin), eczema or hair loss, poor memory, peripheral neuropathies, behavior problems and learning difficulties. Many visual and nervous system disorders are also probably due to DHA deficit [13].

\section{Biosynthesis of the omega-3 PUFAs family}

The biosynthesis process of omega-3 PUFAs generates a series of metabolites, polyunsaturated fatty acids with higher carbon numbers, and a greater number of double bonds from ALA. Once absorbed from the diet, the EFAs LA and ALA are primarily metabolized in the liver, although it is also possible that this takes place in other tissues [14]. The biochemical process of AL and ALA elongation and desaturation occurs in the endoplasmic reticulum and also in the peroxisomes of liver cells or hepatocytes [15]. Linoleic acid (LA) can be metabolized to other more unsaturated long-chain members of the n-6 family by the insertion of additional double bonds during consecutive elongation and desaturation mechanisms. The initial phase of LA (18:2 n-6) to GLA ( $\gamma$-linolenic acid, 18:3 n-6) conversion is by the enzyme delta-6-desaturase (FADS2) [16] and this is then converted to DGLA (dihomo- $\gamma$-linolenic acid 20:3 n-6) by elongation of elongases (ElovL2). Subsequently, DGLA, by the action of delta-5 desaturase (FADS1), is transformed into AA [17]. Finally, a cycle of elongation, desaturation by Delta-6 desaturase (FADS2) and peroximal beta-oxidation generates docosapentaenoic acid (22:5 n-6) [18].

ALA (omega-3 PUFA) is desaturated to 18: $4 \mathrm{n}-3$ (stearidonic acid) by delta- 6 desaturase, elongated to 20: 4 n-3 (eicosatetraenoic acid) and then converted to 20: 5 n-3 (EPA) in the endoplasmic reticulum (RE) by delta-5 desaturase. Subsequently, EPA by action of elongase is transformed into 22: $5 \mathrm{n}-3$ (docosapentaenoic acid), which continues to elongate at 24: $5 \mathrm{n}-3$ (tetracosapentaenoic acid), followed by desaturation by delta- 6 desaturase of 24: $6 \mathrm{n}-3$ (tetracosahexaenoic acid). Subsequently, this acid is transferred to the peroxisomes, and finally converted to 22: $6 \mathrm{n}-3$ (DHA) by removing 2 carbons from the chain by beta-oxidation (Figure 2). Aretroconversion of DHA to EPA omega-3 PUFAs is also possible, although this type of metabolic process is relatively limited in man [19]. Retroconversion includes a beta-oxidation cycle with some auxiliary enzymes [20], but Brossard et al. [21] calculated that the retro conversion rate of DHA to EPA in humans receiving normal dietary amounts of DHA is only $\approx 1.4 \%$.

While dietary ALA can be converted to DHA and EPA, this is a slow process [22,23] and the extent of this conversion appears to be minimal during common intake $[24,25]$ in humans as well as in rodents and other mammals [26,27]. ALA is metabolized 
to EPA and DHA more efficiently in women than the men. The female capacity to convert ALA to EPA is $\approx 21 \%$,with $\approx 9 \%$ being converted to DHA, and a concomitant reduction in the rate of ALA oxidation $(\approx 22 \%$ compared with $\approx 33 \%$ in men) $[25,28,29]$. These differences in metabolism may be attributed to the regulatory effects of estrogens [30], and this ability to increase the conversion of ALA in women possibly being important to meet the demand for DHA in the neonate and fetus [31]. It is well established that DHA can be biosynthesized from the short chain precursor ALA, through the elongation and desaturation processes of its hydrocarbon chain [32] (Figure 2). LA and ALA are metabolized by the same enzymes and therefore compete for them, with these metabolic processes not being interchangeable [33]. The Omega-3 and omega-6 PUFAs compete for the desaturase enzymes (FADS1 and FADS2) and have a higher affinity for ALA than LA [22,23,34].

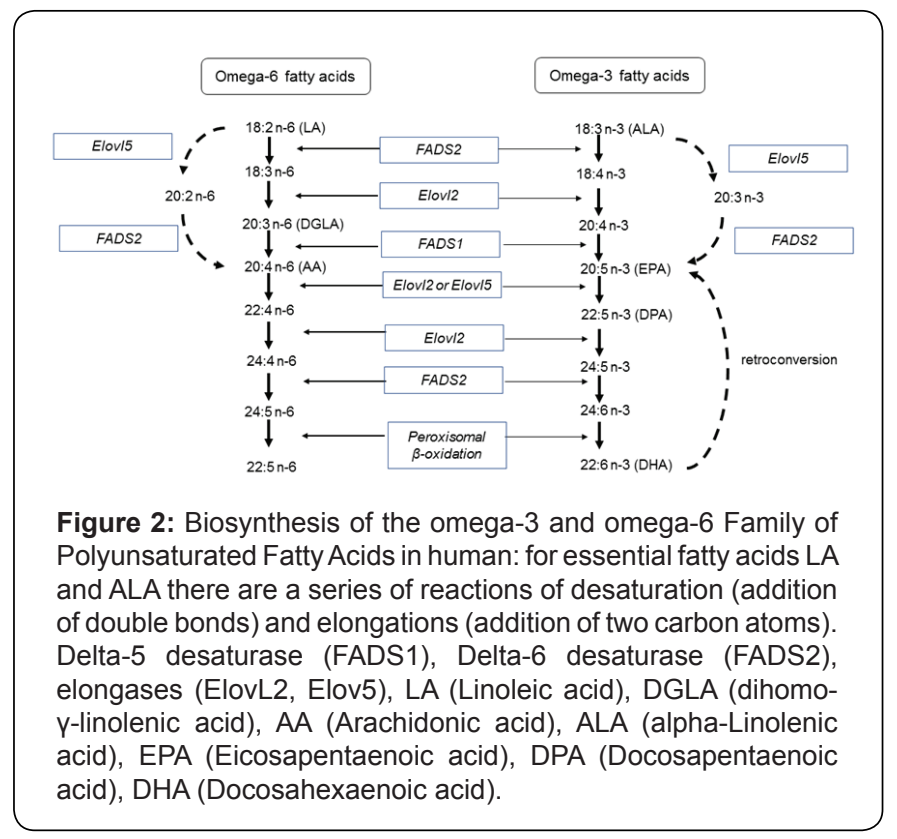

\section{0mega-3 PUFAs and pain}

The diet should not only provide EFAs, but also the omega-3 and omega- 6 PUFAs, with the balance between these PUFAs being critical as it greatly influences human health.Omega-3 and Omega-6 PUFAs compete with same metabolic enzymes and position of the phospholipids, but they often have important opposing physiological effects [35]. AA is a major intermediate omega-6 PUFA that competes with DHA for the same elongation and desaturation enzymes. However, a diet with ALA (omega-3 PUFA) induces suppressive effects on the metabolism of omega- 6 PUFAs, whereas omega-6 PUFA has a 10-fold suppressive effect lower on the metabolism of omega-3 PUFAs [36]. Therefore, an abundant diet of LA produces a suppression of the ALA to DHA conversion [37]. Also, AA competes with DHA for the sn-2 position of phospholipids in cellular membranes [38].

The omega-6 PUFAs produce metabolites with inflammatory, procoagulant and vasoconstrictor actions, processes that are vital for the body's immune system's ability to repair and protect itself. In contrast, omega-3 PUFAs metabolites counteract the effects of omega-6, being anti-inflammatory, anticoagulant, and vasodilators [39-41]. The high LA content of modern industrialized diets can generate a physiological situation that favors chronic inflammation, heart disease, diabetes, autoimmune arthritis and impaired neuronal functioning, including mental disorders [42-45] and the development of chronic pain [46].

When humans ingest fish or fish oil, the EPA and DHA from the diet partially replace the omega-6 PUFAs (especially AA) in the membranes of probably all cells, but especially in the membranes of platelets, erythrocytes, neutrophils, monocytes, and liver cells (reviewed in (541) [47]. Clinical studies have shown some benefits resulting from the use of omega-3 PUFAs (EPA and DHA) for different inflammatory pains, such as inflammatory joint pain, inflammatory bowel disease, chronic headaches, knee osteoarthritis, rheumatoid arthritis, neck or back pain, neuropathic pain, musculoskeletal injury and dysmenorrheal [48]. In addition, some studies have demonstrated that omega-3 PUFAs can significantly reduce then onsteroidal anti-inflammatory drug (NSAIDs) requirement in patients with mild rheumatoid arthritis [49-62].

The role of omega-3 PUFAs in pain has also been investigated in rodents, with Yehuda et al. [63] being one of the first to report on the effects of how diet can modify the response of rodents to acute and chronic nociceptive stimuli. In this investigation, animals fed on a soybean oil diet with polyunsaturated vegetable fat for three weeks demonstrated an increase in the pain threshold. Furthermore, these authors reported the effect of different omega-3: omega- 6 ratios in the diet and found that an increase inALA-omega-3 PUFA led an analgesic effect.

Other investigations using fish oil (18\% EPA and 12\% DHA) and fish oil concentrate (46.5\% EPA and 37.5\% DHA) have demonstrated an antinociceptive effect after their chronic administration $[64,65]$, including after acute oral administration at low doses [66]. Related to this, some studies have shown antinociceptive effects against various pain stimuli (thermal and chemical nociception) after acute administration of DHA in mice [67-69]. In an experimental animal model of Complete Freund's Adjuvant-induced knee arthritis, the chronic administration of chronic DHA produced antinociceptive and anti-inflammatory effects [70]. However, no data are available about EPA alone in pain treatment.

Although the exact mechanisms by which omega-3 PUFAs reduce pain is still not fully defined in molecular terms, recent studies have revealed that the antinociceptive effect ofomega-3 PUFAs occurs through the following different mechanisms:

a) Inhibition of the production of the lipid mediator from the arachidonic acid cascade, as the latter contributes to pain and inflammation $\left(\mathrm{PGE}_{2}\right)[71]$ and hyperalgesia $\left(\mathrm{LTB}_{4}\right)$ $[72,73]$. 
b) Production of lipid mediator from EPA and DHA withanalgesic action, such as the E-series (RvE1, RvE2) and D-series (RvD1, RvD2) resolving, respectively, which are potent analgesics [74-78].

c) Regulation of both the peripheral and central transient receptor potential of vanilloid 1 (TRPV1) and acid-sensing ion channels (ASICs).The TRPV1 receptor is a lig and-gated non-selective caution channel activated by heat ( $>43$ degrees C), low $\mathrm{pH}$ and endogenous lipid molecules, with TRPV1 receptor stimulation by endocannabinoids or by capsaicin leading to analgesia [79]. ASICs are permeable to cations and are activated by extracellular acidosis. As ASICs are known to contribute to pain, the stimulation of ASICs in either the CNS or the PNS produces this [80]. Interestingly, whereas DHA is a potent TRPV1 agonist, EPA inhibits the activation of this caution channel by various agonists [81].

d) Release of $\beta$-endorphin by action of DHA through the G-protein-coupled receptor 40 (GPR40 signaling, which finally induces antinociception by the stimulation of the $\mu$ and $\delta$-opioid receptors $[68,69]$.

e) Release of the epoxidized metabolites derived from omega-3 PUFAs DHA (epoxydocosapentaenoic acid, EDP) and EPA (epoxyeicosatetraenoic acid, EEQ), which have an analgesic action $[82,83]$ (Figure 3).

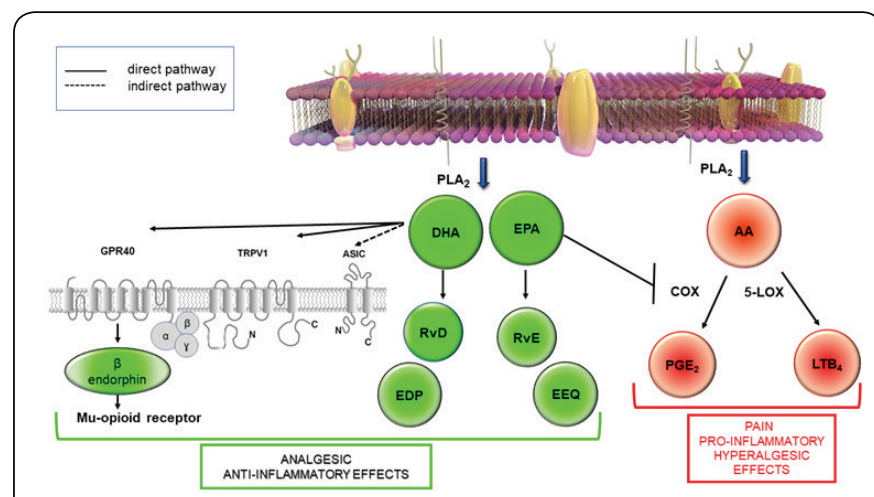

Figure 2: Model illustrating the analgesic mechanism of action of the omega-3 PUFA. Key: GPR40 (G-protein-coupled receptor 40), TRPV1 (transient receptor potential vanilloid 1), ASIC (AcidSensing Ion Channel), EEQ (epoxyeicosatetraenoic acid), EDP (epoxydocosapentaenoic acid), RvD (resolvin D), RvE (resolvin E), PGE2 (Prostaglandin E2), PLA ${ }_{2}$ (Phospholipase $A_{2}$ ).

\section{Morphine therapy in cancer and non-cancer pain}

The prevalence of cancer has been increasing, with a projection estimated by 2020 of 2017 million new cases [84], which implies that there will be a corresponding increase in individuals of pain caused by the disease and by its treatments [85]. In fact, approximately $50 \%$ of patients with cancer suffer from pain at the time of diagnosis, with about $80 \%$ of patients with advanced cancer experiencing moderate to severe pain [86]. In the older adult population, it is estimated that more than $50 \%$ have a chronic pain disorder, with the rate of prevalence substantially higher in the long-term care setting (49\%-89\%) [87].

Pain in the patient with cancer is a problem that involves many people, including the patient and family, doctors, nurses, health authorities and medical education bodies, because to some extent we are all affected by the patient's cancer pain if it is not treated properly. Related to this, it is estimated that this pain is not well treated in as much as $50 \%$ to $80 \%$ of these patients, who have indicated not having received satisfactory relief [88]. Opioids are the most effective analgesics for severe pain and are a first-line treatment option to acute and terminal cancer pain treatments [89]. In addition, in recent years, an increasing trend in the prescription of opioids for non-cancer patients has been observed $[90,91]$, which may be appropriate for the treatment of chronicnon-cancer pain such as low back pain [92] and for neuropathic pain [93], when the pain is intense, continuous and unresponsive to other analgesic standards.

Morphine causes a wide range of adverse effects, with early symptoms usually including somnolence and nausea, and constipation being the most important problem in long-term treatment. Further potential side-effects are euphoria, dysphoria, anxiety, pruritus, urticaria, weight loss bronchospasms, headaches and miosis. However, severe reactions such as respiratory depressions and pronounced hypotension are uncommon when the drug is only used in therapeutic doses. The adverse effects of morphine often constitute significant problems in clinical practice, with most patients (up to 80\%) with chronic pain having reported having at least one adverse effect [94]. Tolerance refers a phenomenon in which exposure to a drug results in the diminution of an effect or the need for higher dose to maintain the effect [95]. Unfortunately, both acute and chronic administration of morphine may produce a rapid onset of analgesic tolerance, which is manifested over time in a reduction in the analgesic effect at the same dose, which then necessitates large daily doses to obtain the same efficacy [96]. Similarly, although opioid medications can provide essential pain relief for many patients, the development of some adverse effects and analgesic tolerance can have a significant impact on the quality of life and result in patients abandoning their treatment altogether.

\section{Omega-3 PUFAs combined with morphine}

Recently, some new strategies have been described for older adults to manage opioid-induced adverse effects, which can be implemented both before and during opioid treatment: dose reduction, opioid rotation, altering the route of opioid administration, and symptomatic management of adverse effects [97]. In addition, other strategies have been proposed in clinical practice to manage morphine-induced adverse effects, such as the use of adjuvants to opioids for the treatment of pain. This combination seeks alternatives to opioids for greater analgesia and the attenuation of opioid-induced adverse 
reactions, such as nausea and vomiting, constipation, sedation, and respiratory depression. Many different classes of drugs can serve as effective adjunctsto opioids for pain treatment, such as nonopioid analgesics (nonsteroidal anti-inflammatory drugs such as aspirin, acetaminophen, ibuprofen and ketoprofen), antidepressants (eg, tricyclics, SSRIs), anticonvulsants (eg, carbamazepine, gabapentin), antiarrhythmics (eg., mexiletine) and sedatives, anxiolytics, tranquilizers (benzodiazepines such as alprazolam) [98]. However, these combined treatments canalso increase the risk for adverse treatment outcomes [87].

Beneficial effects have been observed after a combined treatment with morphine and omega-3 PUFA in an animal model of pain. For example; chronic morphine treatment displayed additive effects when combined with omega-3 PUFAs [65]. Surprisingly, even sub effective doses of morphine have been shown to potentiate omega-3 PUFAs antinociceptive effects [99]. Also, it has been observed that chroniccoadministration of morphine with omega-3 PUFAs attenuated or blocked the development of time-dependent tolerance with some adverse effects also have been diminished [65]

\section{Conclusion}

The findings discussed in this review suggest that omega- 3 PUFAs is a viable alternative to pain treatment in various clinical situations and can provide clear benefits when used as adjuncts to morphine in chronic and acute pain treatment, with one of the most significant advantages of a combination treatment being the possible reduction of morphine side effects, which often acts as a major obstacle in pain treatment. Moreover, the use of a pharmaceutical formulation with a sub effective dose of morphine in combination with omega-3 PUFAs has been shown to improve the quality of pain relief and to reduce adverse events.

\section{Acknowledgment}

I thank Dr. Paul Hobson, native speaker, for revision of the manuscript.

\section{References}

1. Elahe A, Mohammand AS (2014) Long chain polyunsaturated fatty acid sources and evaluation of their nutritional and functional properties. Food Sci Nutr 2(5): 443-446.

2. Ruiz López N, Sayanova O, Napier JA, Haslam RP (2012) Metabolic engineering of the omega 3 long chain polyunsaturated fatty acid biosynthetic pathway into transgenic plants. J Exp Bot 63(7): 23972410 .

3. Bergé JP, Barnathan G (2005) Fatty acids from lipids of marine organisms: molecular biodiversity, roles as biomarkers, biologically active compounds, and economical aspects. Adv Biochem Eng Biotechnol 96: 49-125.

4. Strobel C, Jahreis G, Kuhnt K (2012) Survey of $n 3$ and $n 6$ polyunsaturated fatty acids in fish and fish products. Lipids Health Dis 11: 144

5. Miller MR, Nichols PD, Carter CG (2008) n 3 Oil sources for use in aquaculture alternatives to the unsustainable harvest of wild fish. Nutr Res Rev 21(2): 85-96
6. Kuhnt K, Degen C, Jaudszus A, Jahreis G (2012) Searching for health beneficial $\mathrm{n} 3$ and $\mathrm{n} 6$ fatty acids in plant seeds. Eur J Lipid Sci Technol 114(2): 153-160.

7. Kaur N, Chugh V, Gupta AK (2014) Essential fatty acids as functional components of foods a review. J Food Sci Technol 51(10): 2289-2303.

8. Gebauer SK, Psota TL, Harris WS, Kris Etherton PM (2006) n 3 fatty acid dietary recommendations and food sources to achieve essentiality and cardiovascular benefits. Am J ClinNutr 83 (6 Suppl): 1526S-1535S

9. Connor WE, Neuringer M, Reisbick S (1992) Essential fatty acids: the importance of $n-3$ fatty acids in the retina and brain. Nutr Rev 50: 2129.

10. Colquhoun I, Bunday S (1981) A lack of essential fatty acids as a possible cause of hyperactivity in children. Med Hypotheses 7(5): 673679.

11. Futterman S, Downer JL, Hendrickson A (1971) Effect of essential fatty acid deficiency on the fatty acid composition, morphology, and electroretinographic response of the retina. Invest Ophthalmol 10(2): 151-156.

12. Uauy R, Hoffman DR (1991) Essential fatty acid requirements for normal eye and brain development. Semin Perinatol 15(6): 449-455.

13. Innis SM (1996) Essential dietary lipids. Present Knowledge in Nutrition. In: EE Ziegler, LJ Filer Jr. (Eds.), (7 ${ }^{\text {th }}$ edn.), ILSI Press, Washington DC, USA, p.58-66.

14. Hughes CL, Dhiman TR (2002) Dietary compounds in relation to dietary diversity and human health. J Med Food Summer 5(2): 51-68.

15. Arteburn LM, Hall EB, Oken H (2006) Distribution, interconversion, and dose response of $\mathrm{n} 3$ fatty acids in humans. Am J ClinNutr 83(6 Suppl): 1467S-1476S.

16. Stoffel W, Holz B, Jenke B, Erika B, Mario T, et al. (2008) $\Delta 6$ Desaturase (FADS2) deficiency unveils the role of $\omega 3$ and $\omega 6$ polyunsaturated fatty acids. EMBO J 27 (17): 2281-2292.

17. Moon YA, Hammer RE, Horton JD (2009) Deletion of ELOVL5 leads to fatty liver through activation of SREBP $1 c$ in mice. J Lipid Res 50(3): 412-423.

18. Schmitz G, Ecker J (2008) The opposing effects of n-3 and n-6 fatty acids. Prog Lipid Res 47(2): 147-55.

19. Harris WS (1989) Fish oils and plasma lipid and lipoprotein metabolism in humans: a critical review. J Lipid Res 30(6): 785-807.

20. Osmundsen H, Bremer J, Pederson JI (1991) Metabolic aspects of peroxisomal beta oxidation. Biochem Biophys Acta 1085(2): 14-58.

21. Brossard N, Croset M, Pachiaudi C, Riou JP, Tayot JL, et al. (1996) Retroconversion and metabolism of $\left[{ }^{13} \mathrm{C}\right] 22: 6 \mathrm{n}-3$ in humans and rats after intake of a single dose of $\left[{ }^{13} \mathrm{C}\right] 22: 6 \mathrm{n}-3$ triacylglycerols. Am J ClinNutr 64: 577-586.

22. De Gomez Dumm INT, Brenner RR (1975) Oxidative desaturation of alphalinolenic, linoleic, and stearic acids by human liver microsomes. Lipids 10(6): 315-317.

23. Emken EA, Adlof RO, Rakoff H, Rohwedder WK (1989) Metabolism of deuterium labeled linolenic, linoleic, oleic, stearic and palmitic acid in human subjects. In Synthesis and Application of Isotopically Labeled Compounds, Aillie TA, Jones JR (Eds.), Elsevier Science Publishers: Amsterdam, Netherlands, pp. 713-716.

24. Emken EA, Adlof RO, Gulley RM (1994) Dietary linoleic acid influences desaturation and acylation of deuterium labeled linoleic and linolenic acids in young adult males. BiochimBiophys Acta 1213(3): 277-288.

25. Burdge GC, Wootton SA (2002) Conversion of alpha linolenic acid to eicosapentaenoic, docosapentaenoic and docosahexaenoic acids in young women. Br J Nutr 88(4): 411-420. 
26. Woods J, Ward G, Salem N (1996) Is Docosahexaenoic Acid Necessary in Infant Formula? Evaluation of High Linolenate Diets in the Neonatal Rat. Pediatr Res 40(5): 687-694.

27. Williams CM, Burdge G (2006) Long chain n 3 PUFA: plant v. marine sources. Proc NutrSoc 65(1): 42-50.

28. Burdge GC, Jones AE, Wootton SA (2002) Eicosapentaenoic and docosapentaenoic acids are the principal products of alpha linolenic acid metabolism in young men. Br J Nutr 88(4): 355-363.

29. Burdge GC, Finnegan YE, Minihane AM, Williams CM, Wootton SA (2003) Effect of altered dietary n-3 fatty acid intake upon plasma lipid fatty acid composition, conversion of $\left[{ }^{13} \mathrm{C}\right]$ alpha linolenic acid to longer chain fatty acids and partitioning towards beta oxidation in older men. Br J Nutr 90(2): 311-321.

30. Burdge GC, Calder PC (2005) Conversion of $\alpha$ linolenic acid to longer chain polyunsaturated fatty acids in human adults. ReprodNutr Dev 45(5): 58-597.

31. Gorjáo R, Azevedo Martins AK, Rodrigues HG, Addulkader F, Arcesio Miranda M, et al. (2009) Comparative effects of DHA and EPA on cell function. Pharm Ther 122(1): 56-64.

32. Sprecher H (2000) Metabolism of highly unsaturated n 3 and n 6 fatty acids. Biochem Biophys Acta 1486(2 3): 219-231.

33. Simopoulos AP (2010) Genetic variants in the metabolism of omega 6 and omega 3 fatty acids: their role in the determination of nutritiona requirements and chronic disease risk. Exp Biol Med (Maywood) 235(7): 785-795.

34. Hague TA, Christoffersen BO (1984) Effect of dietary fats on arachidonic acid and eicosapentaenoic acid biosynthesis and conversion to C22 fatty acids in isolated liver cells. BiochimBiophys Acta 796(2): 205217.

35. Schmitz G, Ecker J (2008) The opposing effects of $n-3$ and $n-6$ fatty acids. Prog Lipid Res 47(2): 147-55.

36. Holman RT (1998) The slow discovery of the importance of omega 3 essential fatty acids in human health. J Nutr 128(2 Suppl): 427S-433S.

37. Smink W, Gerrits WJJ, Gloaguen M, Ruiter A, van Baal J (2012) Linoleic and $\alpha$ linolenic acid as precursor and inhibitor for the synthesis of long chain polyunsaturated fatty acids in liver and brain of growing pigs. Animal 6(2): 262-270

38. Vance DE, Vance JE (2008) Phospholipid Biosynthesis in Eukaryotes. In Vance DE, Vance JE (Eds.), ( $5^{\text {th }}$ edn.), Biochemistry of Lipids, Lipoproteins and Membranes. Elsevier, St. Louis, USA, pp. 213244.

39. Bagga D, Wang L, Farias Eisner R, Glaspy JA, Reddy ST (2003) Differential effects of prostaglandin derived from omega 6 and omega_3 polyunsaturated fatty acids on COX 2 expression and IL 6 secretion. Proc Natl Acad Sci USA 100(4): 1751-1756.

40. Robinson JG, Stone NJ (2006) Antiatherosclerotic and antithrombotic effects of omega 3 fatty acids. Am J Cardiol 98(4A): 39i-49i.

41. Simopoulos AP (1999) Essential PUFAs in health and chronic disease. Am J ClinNutr 70: S560-S569.

42. Cannor WE (2000) Importance of $\mathrm{n} 3$ fatty acids in health and disease. Am J ClinNutr 71 (1 Suppl): 171S-175S.

43. James, MJ and Leaf, A (2000) Prevention of fatal cardiac arrhythmias by polyunsaturated fatty acids. Am J ClinNutr 71(1 suppl): 202-207.

44. Kremer JM (2000) N 3 Fatty acid supplements in rheumatoid arthritis. Am J ClinNutr 71(1 suppl): 349-351.

45. Calder PC (2006) n 3 polyunsaturated fatty acids, inflammation, and inflammatory diseases. Am J ClinNutr 83(6 Suppl ): 1505S-1519S.

46. Ramsden CE, Ringel A, Majchrzak Hong SF, Yang J, Blanchard $\mathrm{H}$ et al. (2016) Dietary linoleic acid induced alterations in pro and anti nociceptive lipid autacoids: Implications for idiopathic pain syndromes? Mol Pain 10: 12.

47. Simopoulos AP (2008) The importance of the omega 6/omega 3 Fatty Acid ratio in cardiovascular disease and other chronic diseases. ExpBiol Med 233(6): 674-688.

48. Toledo ME, Laino CH (2017) Omega 3 Polyunsaturated Fatty Acids: A New Option in the Treatment of Pain in: Omega 3: Dietary Sources, Biochemistry and Impact on Human Health. In Sean J Moore (eds.) Nova Science Publishers, USA, pp. 31-78.

49. Berbet AA, Kondo CR, Almendra CL, Matsuo, Dichi I (2005) Supplementation of fish oil and olive oil in patients with rheumatoid arthritis. Nutrition 21(2): 131-136

50. Kremer JM, Lawrence DA, Petrillo GF, Litts LL, Mullaly PM, et al (1995) Effects of high dose fish oil on rheumatoid arthritis after stopping nonsteroidal antiinflammatory drugs: clinical and immune correlates. Arthritis Rheum 38(8): 1107-1114.

51. Sundrarjun T, Komindr S, Archararit N, Dahlan W, Angthararak S, Chuncharunee $S$, et al. (2004) Effects of n 3 fatty acids on serum interleukin 6, tumour necrosis factor alpha and soluble tumour necrosis factor receptor p55 in active rheumatoid arthritis. J Int Med Res 32(5): 443-454

52. Nordstrom DC, Honkanen VE, Nasu, Y, Antla E, Friman, et al. (1995) Alpha linolenic acid in the treatment of rheumatoid arthritis. A double blind, placebo controlled and randomized study: flaxseed vs. safflower seed. RheumatolInt 14(6): 231-234.

53. Lau CS, Morley KD, Belch JJ (1993) Effects of fish oil supplementation on non steroidal anti inflammatory drug requirement in patients with mild rheumatoid arthritis a double blind placebo controlled study. Br J Rheumatol 32(11): 982-989.

54. Nielsen GL, Faarvang, KL, Thomsen BS, KL Teglbaerg, LT Jensen, et al (1992) The effects of dietary supplementation with $n 3$ polyunsaturated fatty acids in patients with rheumatoid arthritis: a randomized, double blind trial. Eur J Clin Invest 22(10): 687-691.

55. Skoldstam L, Borjesson O, Kjallman A, Seiving B, Akesson (1992) Effect of six months of fish oil supplementation in stable rheumatoid arthritis. A double blind, controlled study. Scand J Rheumatol 21(10): 178-185.

56. Tulleken JE, Limburg PC, Muskiet FA, Van Rijswijk MH (1990) Vitamin E status during dietary fish oil supplementation in rheumatoid arthritis. Arthritis Rheum 33(9): 1416-1419.

57. Van Der Tempel H, Tulleken JE, Limburg PC, Van Rijswijk MH, Muskiet FA (1990) Effects of fish oil supplementation in rheumatoid arthritis. Ann. Rheum Dis 49(2): 76-80.

58. Cleland L, French JK, Betts WH, Murphy GA, Elliott MJ (1988) Clinical and biochemical effects of dietary fish oil supplements in rheumatoid arthritis. J Rheumatol 15(10): 1471-1475.

59. Galarraga B, Ho M, Youssef HM, Hill A, McMahon H, et al. (2008) Cod liver oil (n 3 fatty acids) as a non steroidal anti inflammatory drug sparing agent in rheumatoid arthritis. Rheumatology (Oxford) 47(5): 665- 669.

60. Belch JJF, Ansell D, Madhok R, Dowd AO, Sturock RD (1988) Effects of altering dietary essential fatty acids on requirements for non steroidal anti inflammatory drugs in patients with rheumatoid arthritis: a double blind placebo controlled study. Ann Rheum Dis 47(2): 96-104.

61. Kjeldsen Kragh J, Lund JA, Riise T, finnanger B, Haaland K, et al. (1992) Dietary omega 3 fatty acid supplementation and naproxen treatment in patients with rheumatoid arthritis. J Rheumatol 19(10): 1531- 1536.

62. Park Y, Lee A, Shim SC, Lee JH, Choe JY, et al (2013) Effect of $n$ 3 polyunsaturated fatty acid supplementation in patients with 
rheumatoid arthritis: a 16 week randomized, double blind, placebo controlled, parallel design multicenter study in Korea. J. NutrBiochem 24(7): 1367-1372.

63. Yehuda S, Leprohon Greenwood CE, Dixon LM, Coscina DV (1986) Effects of dietary fat on pain threshold, thermoregulation and motor activity in rats. PharmacolBiochemBehav 24(6): 1775-1777.

64. Veigas JM, Williams PJ, Halade G, Rahman MM, Yoneda T, et al. (2011) Fish oil concentrate delays sensitivity to thermal nociception in mice. Pharmacol Res 63(5): 377-382.

65. Escudero GE, Romañuk CB, Toledo ME, Olivera ME, Manzo RH, et al. (2015) Analgesia enhancement and prevention of tolerance to morphine: beneficial effects of combined therapy with omega 3 fatty acids. J Pharm Pharmacol 67(9):1251-1262.

66. Nobre ME, Correia AO, Borges M de B, et al. (2013) Eicosapentaenoic acid and docosahexaenoic acid exert anti inflammatory and antinociceptive effects in rodents at low doses. Nutr Res 33(5): 422 433

67. Nakamoto K, Nishinaka T, Mankura M, Fujita Hamabe W, Tokuyama S (2010) Antinociceptive effects of docosahexaenoic acid against various pain stimuli in mice. Biol Pharm Bull 33(6):1070-1072.

68. Nakamoto K, Nishinaka T, Ambo A, Mankura M, Kasuya F, et al. (2011) Possible involvement of beta endorphin in docosahexaenoic acid induced antinociception. Eur J Pharmacol 666(1 3): 100-104.

69. Nakamoto K, Nishinaka T, Matsumoto K, Kasuya F, Mankura M, et al. (2012) Involvement of the long chain fatty acid receptor GPR40 as a novel pain regulatory system. Brain Res1432: 74-83.

70. Torres Guzman AM, Morado Urbina CE, Alvarado Vazquez PA, Acosta Gonzalez RI, Chavez Piña AE, et al. (2014) Chronic oral or intraarticular administration of docosahexaenoic acid reduces nociception and knee edema and improves functional outcomes in a mouse model of Complete Freund's Adjuvant-induced knee arthritis.Arthritis Res Ther 16(2): R64.

71. Kawabata A (2011) Prostaglandin E2 and pain an update. Biol Pharm Bull 34(8): 1170-1173.

72. Levine JD, Lau W, Kwiat G, Goetzl EJ (1984) Leukotriene B4 produces hyperalgesia that is dependent on polymorphonuclear leukocytes. Science 225: 743-745.

73. Bennett G, al Rashed S, Hoult JR, Brain SD (1998) Nerve growth factor induced hyperalgesia in the rat hind paw is dependent on circulating neutrophils. Pain77: 315-322.

74. Leslie CC (2004) Regulation of arachidonic acid availability for eicosanoid production. Biochem Cell Biol 82(1): 1-17.

75. Piomelli D (1993) Arachidonic acid in cell signaling. Curr Opin Cell Biol 5(2): 274-280.

76. Capdevila JH, Falck JR, Estabrook RW (1992) Cytochrome P450 and the arachidonate cascade. FASEB J 6:731-736.

77. Shimizu T, Wolfe LS (1990) Arachidonic acid cascade and signal transduction. JNeurochem 55(1): 115.

78. Calder PC, Yaqoob P, Thies F, Wallace FA, Miles EA, et al. (2002) Fatty acids and lymphocyte functions. Br J Nutr 87: S31-S48.

79. Palazzo E, Rossi F, Maione S (2008) Role of TRPV1 receptors in descending modulation of pain. Mol Cell Endocrinol 286 (1-2 Suppl 1): S79-S83.

80. Wemmie JA, Taugher RJ, Kreple CJ (2013) Acid sensing ion channels in pain and disease. Nat Rev Neurosci 14(7):461-471.
81. Smith WL, De Witt DL, Garavito RM (2000) Cyclooxygenases: structural, cellular, and molecular biology. Annu Rev Biochem 69:145-182.

82. Wagner K, Vito S, Inceoglu B, Hammock BD (2014) The role of long chain fatty acids and their epoxide metabolites in nociceptive signaling. Prostaglandins \& other lipid mediators 113-115: 2-12.

83. Morisseau C, Inceoglu B, Schmelzer K, Tsai HJ, Jinks SL, et al. (2010) Naturally occurring monoepoxides of eicosapentaenoic acid and docosahexaenoic acid are bioactive antihyperalgesic lipids. Journal of Lipid Research 51(12), 348- 3490.

84. Kanavos P (2006) The rising burden of cancer in the developing world. Ann Oncol 17: 15-23.

85. Paice JA (2011) Chronic treatment related pain in cancer survivors. Pain 152(3 suppl): S84-S89.

86. Donnelly S, Walsh D (1995) The symptoms of advanced cancer. SeminOncol 22 (2 suppl 3):67-72.

87. Ayres E, Warmington M, Reid MC (2012) Chronic pain perspectives: Managing chronic pain in older adults: 6 steps to overcoming medication barriers. J Fam Pract 61(9 Suppl): S16-S21.

88. Bonica JJ (1985) Treatment of pain: current status and future needs. In Fields HL (Eds.) Advances in pain research and therapy. New York: Raven Press pp. 589-616.

89. Ballantyne JC (2003) Chronic pain following treatment for cancer: the role of opioids. Oncologist 8(6): 567-575.

90. Manchikanti LA, Singh A (2008) Therapeutic opioids: a ten year perspective on the complexities and complications of the escalating use, abuse, and nonmedical use of opioids. Pain Physician 11(suppl 2): S63-S88.

91. Thielke SM, Simoni Wastila L, Edlund MJ, DeVries A, Martin BC, et al. (2010) Age and Sex trends in long term opioid use in two large american health systems between 2000 and 2005. Pain Medicine 11(2): 248256.

92. Chou R, Huffman LH (2007) Medications for acute and chronic low back pain: a review of the evidence for an American Pain Society/ American College of Physicians Clinical Practice Guideline. Ann Intern Med 147: 505-514.

93. Eisenberg E, McNicol ED, Carr DB (2005) Efficacy and safety of opioid agonists in the treatment of neuropathic pain of nonmalignant origin: systematic review and Meta analysis of randomized controlled trials. JAMA 293(24): 3043-3052.

94. Dumas EO, Pollack GM (2008) Opioid Tolerance Development: Pharmacokinetic/ Pharmacodynamic Perspective. AAPS J 10 (4): 537.

95. Collett BJ (1998) Opioid tolerance: the clinical perspective. British Journal of Anaesthesia 81(1): 5868.

96. Franklin GM (2014) Opioids for chronic noncancer pain A position paper of the American Academy of Neurology 83(14):1277-1284.

97. Rogers E, Mehta S, Shengelia R, Reid MC (2013) Four Strategies for Managing Opioid Induced Side Effects in Older Adults. ClinGeriatr 21(4):1201.

98. Goldstein FJ (2002) Adjuncts to opioid therapy. J Am Osteopath Assoc 102(9 Suppl 3): S15-S21.

99. Laino C, Romañuk CB (2012) Universidad Nacional de Córdoba, Universidad Nacional de la Rioja and CONICET, assignee. Composición farmacéutica para el tratamiento del dolor, procedimiento de obtención y métodos de tratamiento. Argentina Patent Application P 20120100854. 
(C) (1) This work is licensed under Creative BY DOI: $10.19080 / J P C R .2017 .03 .555610$

\section{Your next submission with Juniper Publishers will reach you the below assets}

- Quality Editorial service

- Swift Peer Review

- Reprints availability

- E-prints Service

- Manuscript Podcast for convenient understanding

- Global attainment for your research

- Manuscript accessibility in different formats ( Pdf, E-pub, Full Text, Audio)

- Unceasing customer service

Track the below URL for one-step submission https://juniperpublishers.com/online-submission.php 